\title{
Research on the Formation and Development of Express Industry in Europe and America
}

\author{
Jingxian Huang \\ Business Department \\ Guizhou Minzu University \\ Guiyang, China
}

\begin{abstract}
Research on the express delivery market in Europe and the United States needs to be analyzed from two aspects: market of Parcel Delivery and Express Delivery. The representative company providing Parcel Delivery service is UPS, and the most representative enterprise providing Express Delivery service is FedEx, both of which are representative integrators in the United States. This article expounds the formation and development of the U.S. express market centering on the development of FedEx.
\end{abstract}

Keywords—parcel delivery; express delivery; integrator; international express

\section{INTRODUCTION}

With the innovation of logistics information system brought by the information technology revolution, business mode of international express achieves rapid innovative development. At the same time, the merger and reorganization of logistics enterprises has promoted the upgrading of the world's logistics enterprises. This article elaborates the development and formation of the U.S. airport express market and the current competition pattern.

\section{COMPETITION PATTERN OF AMERICAN EXPRESS MARKET}

The express delivery market in Europe and the United States consists of two aspects: Parcel Delivery market and Express Delivery market. The representative company providing Parcel Delivery service is UPS, and the most representative enterprise providing Express Delivery service is FedEx. From the development history of the two companies, UPS was originally a trucking company. Since 1980, with the decentralization of the air transport industry, it began to own its own aircraft carriers, and became the representative integrator in the world. FedEx originally provided air services, and provides the next-day delivery express service in the United States. After that, it built a land transport network to become a representative integrator providing Express services in the world market.

Parcel Delivery market in the United States is mainly composed of the five companies including UPS, FedEx,

Soft Science Foundation Project of Guizhou Science and Technology Department, project number: science cooperation foundation of Guizhou [2017] 1515-6 Project Name: research on the innovative development of cross-border e-commerce.
United States Postal Service (USPS), Airborne and DHL. Over the past few decades, the small-sized goods delivery industry is constantly merging. Express delivery market in the United States mainly includes four companies of UPS, FedEx, Menlo Worldwide, and BAX Global. The Express Delivery Services industry in the United States emerged in the 1960s in response to a sharp increase in the need for rapid and reliable document delivery services. Subsequently, with the expansion of small and general cargo, development of cargo tracking technology, and need for off-the-shelf production and real-time logistics services, Express Delivery Services industry became more and more important. In addition, the growth of the Internet and online shopping also contributed to the growth of the express delivery industry [1]

As the need for 2-3 days rapid-delivery services in the U.S. market increases, FedEx has expanded its land transport network. With the intense competition in rapid delivery between major cities in U.S., UPS increases the efficiency of its own land delivery network. In addition, UPS and FedEx can provide other value-added services in addition to the delivery service. For example, UPS provides SCM services to large-scale domestic and overseas enterprises in the United States and has established three separate divisions of retail delivery, logistics and financial services. In the international market, FedEx and UPS begin the freight forwarding business, using their own air lanes to provide their customers with third-party logistics services and customs clearance services. The boundary of services provided by Integrator is becoming more and more ambiguous, so the competition between freight forwarding companies, transportation industry and logistics management industry is more and more fierce.

At the same time, with the intensified competition in Express Delivery service, postal service started to enter this field as well, such as Canada Post Corp., Deutsche Post AG La Poste (France), Japan Post, TPG Post (Netherlands), Sweden Post, Consignia plc (UK). [2]

\section{THE DEFINITION OF INTEGRATOR}

Integrator refers to the logistics practitioners who not only own transport vehicles such as air cargo planes but also play a role in freight forwarding. A company can provide transport enterprises with complex logistics services. The international express refers to the door to door service, but 
there is not always air cargo transport aircraft [3]. Representative integrators are UPS and FedEx in the United States, which are logistics enterprises providing comprehensive international logistics services.

With the simplification and decentralization of the United States, many logistics companies enter the air express market. The most representative companies that use hub and spork transport system to rapidly grow up are UPS and FedEx. The hub and spork way is to put the goods collected from all parts of the United States first in the central airport and then sort them to transport to the local airport at the destination by plane for the next day's delivery. Then we can track the goods by using the logistics information system.

The decentralization in the field of American Airlines creates integrators such as UPS and FedEx. Under the background of European postal privatization, the postal commune mergers international express delivery business to gradually develop into an integrator. The representative example is that Deutsche Post mergers Germany DHL after privatization and Post Netherlands mergers TNT to establish the status of integrator.

\section{A. Development of Airmail}

After World War II, it is the postal handling business that promotes the commercialization of aircraft carriers. The U.S. Congress conducted a pilot Postal flight in 1917, but crashes often happen. The charm of using air cargo is well known, so the aviation postal service has not stopped its pace even in the event of a flight accident. A big leap emerged in 1921, when the postal administration tested the U.S. mainland cross-border postal transport and took 33 hours and 20 minutes flying from Los Angeles to New York, which breaks the previous record. Since then, the relatively safer flight of the U.S. mainland has laid a solid foundation and the United States has invested a large amount of capital in infrastructure construction to support the flight across the U.S. mainland.

Here the United States West Airlines needs to be mentioned. At that time, the United States Western Airlines proposed [air postal delivery, indeed! Direct! Daily!], and started the postal flight business. Since then, other companies began to enter the field of airmail, with the price competition also very intense. Boeing Co. seizes the market with low prices, and finally became the giant of the modern aviation industry in the United States.

\section{B. Express Service Corresponding to the Age of Speed}

Fred smith, a navy soldier in the Vietnam War, completed 230 war missions. He got a flying driving license at the age of 15 . His grandfather operated shipping tool over a river and his father ran a route bus between the states in the U.S. It could be said that he was born in a family very close to transportation. Having experienced the brutal war, embracing the fervent hope of contributing to the society, he finally determined to run a business in logistics.

In the United States in the 1970s, with the development of information technology such as computers, the undertakings of various enterprises have entered a period of rapid innovation and growth. At this time, Smith quickly captured the business opportunity of needs of enterprises for speed. Then he proposed the concept of the next-day delivery. He began to consider using aircraft to carry goods. As we all know, Smith's company FedEx established a worldwide express delivery network.

Previously, another company DHL also started the same business. DHL's founders also felt dissatisfied with the airline postal service at the time and saw many business people and businesses are dissatisfied with the speed of postal delivery at that time. Capturing the gap market between the postal service and air cargo, he began to use aircraft to transport some shipping documents between Los Angeles and Hawaii Between. They collect the goods and transport and deliver the goods. For the owners, DHL can indeed deliver shipping documents quickly to the destination of the ship, and thus reduce custodian fees, warehouse fees and other expenses. Although the delivery cost is a little expensive, the overall cost has been reduced a lot. Therefore, the cost of DHL created a great deal of added value for the cargo owner enterprise. DHL's shipping operations was well welcomed, so its service quickly extended to the world. It extended to Philippines in 1971, to Hong Kong in 1971 and to Japan and other Asian countries. It came to Europe in 1974, to South America in 1977, to Africa and the Middle East in 1978, to Eastern Europe in 1983, and to China in 1986, with fierce momentum of development.

FedEx also developed very fast. It set up a huge cargo collection airport in Philippines to collect mobile phone goods from the United States to the world, and then conduct domestic and international goods sorting, and finally transport to all the destinations by plane in the night sky. FedEx proposed the slogan "Absolute, True, Next-Day Delivery," and completed this slogan with absolute confidence.

In the 1990s, computers were basically popularized throughout the world and construction of information systems was completed. In this case, the competitiveness of manufacturing enterprises also began to rely on the advancement of computer and information systems. In this era, logistics theory has also been put forward and applied to the production process. In the production process, the necessary materials and components should be delivered according to the required amount, inventory need to be reduced but cannot run out, which put forward higher requirements for logistics system. In keeping with the pace of the times, FedEx and DHL take over the revolution of logistics by conforming to the trend of the times to become the darlings of the times. [4]

\section{INTEGRATOR AND INTERNATIONAL EXPRESS}

With the internationalization of business activities, the needs of air cargo transportation become higher and higher. International integrators such as FedEx, UPS, DHL, and TNT become more and more active. 


\section{A. History of International Express}

The development of international express delivery is the simplification and decentralization of the transportation industry in the era of Carter administration. When the Cargo Reform Act was established in 1977, the entry restrictions on the air cargo transport industry were repealed and the liberalization of American air cargo shipping began. Small parcel service companies in the United States began to evolve into the air transport industry.

In addition, truck delivery companies began to have their own aircraft and entered the international express delivery market. UPS is a typical representative. In addition, TNT and other postal services began to enter the international express market.

The attractive companies in international air cargo market are the express delivery companies represented by DHL, FedEx, and UPS, also known as the integrator. They direct transport from the owner to the owner combining air transport or truck transport and also provide customs clearance services and other international delivery services. Integrator's strong competitiveness and phenomenal growth speed have drawn wide attention. With the documents and small parcels of very slow postal services of various national governments as the core, the construction of a logistics network centering on speed was started. Although logistics networks vary from company to company, careful service network and high shipping frequency are indispensable. Large-scale hub and spork systems began to be built in various locations in the world, with a certain amount of cargo transport aircraft and certain trucks to carry out international courier service [5].

\section{B. Features of Integrator}

Integrator has had a big impact on the international air cargo market in two aspects. Before using of Integrator, original air cargo was from the airport to the airport. With the improvement of pick-up delivery system, clearance procedures and the preparation of cargo tracking system, a more advanced door-to-door delivery service has become possible.

Integrator makes use of large cargo aircraft to transport goods to efficiently utilize air transport space, entering a field of general cargo transport. Due to its very complete logistics network, the scale and speed pose a threat to competitors. In addition, Integrator provides fast and consistent door-to-door service and possesses a computer system for cargo tracking, so it poses a threat to the status of freight forwarding companies in the international aviation market.

The tricky issue of Integrator is cost. It provides rapid shipping services for high value-added small items, so the whole operating system is designed based on high cost. Therefore, if the quantity of goods is not large enough, profit cannot be made. The higher the efficiency of the logistics network and speed is, the higher the cost is. At that time, the rapid economic growth in the United States and Europe promoted the rapid growth of integrator. At present, the growth of the world economy is becoming passivated and the integrator has to face the problem of high cost. In addition, large-scale transport network is necessary, so it is difficult for most integrators to coexist in the world. M \& A becomes indispensable. Therefore, currently there are only 3-4 integrator companies left.

\section{THE REASON WHY INTERNATIONAL EXPRESS OF INTEGRATOR IS POPULAR}

\section{A. Speed}

Integrator uses its own corporate logistics network for shipping and delivery services. In general, when the shipping company ships the goods, it will go through the agency. However, integrators taking charge of this this procedure by their own enterprises of course will reduce the transport time.

\section{B. Door-to-door Logistics Services}

To begin with, the most important part of the goods transportation is carrying and delivery services. The fast, secure, and reliable door-to-door service provided by integrator now seems to be a well-deserved one, but it is epoch-making.

\section{Problem of Shipping Costs}

Regardless of the cost, the shipping costs of DHL and FedEx are all-inclusive fee. Until then, customs fee and shipping costs were separated in air cargo transport. Consignors and consignees need to deal with many links, and the final total is the transportation costs, which is very difficult to grasp. However, the cost of international express provided by integrator is all-inclusive cost, including the domestic shipping costs and customs clearance fees of the exporting and importing countries are all included. Paying is also a one-time unified payment. It is very simple, so transportation costs are easy to grasp. At the same time, cargo tracking is completely systematic, so now which link the goods are in can be queried. Now it seems ordinary, but in the past the postal business does need to pay additional fee.

\section{Solutions for International Express Logistics}

High-end manufacturers such as automobiles, computers, communications equipment, precision machinery, and various electronic products have undergone the development of globalization and multi-nationalization and need to conduct the production of manufactured parts dispersedly around the world. All kinds of spare parts need to be crossproduced in factories all over the world to produce finished product. At the same time, the cost of warehousing need to be reduced and the delivery time need to be ensured. Therefore, the high capability of logistics with few batches and high frequencies is necessary. In this context, highquality transport management business model like thirdparty logistics and supply chain management was born.

The bulk of general air cargo is relatively large, which has been shipped slowly and it is also the most suitable method. Air cargo simply changed the means of transport from ship to aircraft. In this way, the speed of aircraft is not much utilized. 
International express service of integrator is delivering smaller goods to different door-to-door, thus realizing the delivery of multiple owners. From the perspective of consignee and consignor, the characteristics of international express are essential to the business strategy of the manufacturing place located in various places overseas. Especially for the production with short life cycle such as high-tech related products, inventory reduction of spare parts is necessary, so the timely delivery that international express delivery can achieve is necessary. Therefore, the development speed of DHL and FedEx is staggering.

\section{E. International Express Penetrating into the Individual Level}

Those who use international express most commonly are the legal bodies of enterprise. However, when holidays such as Christmas come, personal express delivery will surge up. When sending Christmas gifts to overseas friends, international courier is easier to operate, and the integrator's international express service can be delivered on time, so international express is loved and welcomed by the individual users. Whether for legal body of enterprise or individual, international express will gradually achieve global development.

\section{CONCLUSION}

In summary, in European and American express delivery market, the delivery company that has achieved great success is the integrator. Integrator integrates land and air networks to provide customers with fast and accurate door-to-door service. Whether in the field of commercial courier or personal express, it wins the user's support. Analysis of the formation and development of domestic and international express delivery market of Europe and the United States is in fact the analysis of the formation and development of integrator.

\section{REFERENCES}

[1] Robinson,Alan, Competition Within The Unit Express Deliver Servicestates Parcel Delivery Market, Association for Postal Commerce, 2003.

[2] United States International Trade Commission,Express Delivery Service:Competitive Conditions Facing U.S. -based Firms in Foreign Markets,Investigation No,332-456 USITC Publication 3678,April 2004.

[3] Takayuki Mori. International courier and integrator. LOGI-BIZ, 2007.3, pp. 82.

[4] Matsushima Shujiro. Rise of international courier service. Take off (Summer), 1999: 34.

[5] Atsutake Yutaka. Improving efficiency in international air cargo market. Transportation prospect (Winter), 1999: 34.

[6] Katsuhiro Yamaguchi. The fast-growing international courier market. transport. 1991. 5: 35-36. 